\title{
Some Recent Developments in the Pharmacology of Heparin
}

WILLaM W. COON, M.D. Ann Arbor, Mich.

\begin{abstract}
LTHOUGH investigations of the pharma$A_{\text {cology of heparin extend back more }}$ than 60 years, much remains to be learned. In spite of the fact that this agent has had a wide and expanding clinical use, it has not been isolated in chemically pure form, its structure is not fully defined, and differences between its anticoagulant and antithrombotic effect have not yet been elucidated. The increasing requirements for heparin for both prophylactic and therapeutic purposes require that current and new knowledge be rapidly assimilated into clinical practice. This commentary reviews briefly and selectively some of the recent developments which may be of practical use in the care of patients or serve as a focus for future research.
\end{abstract}

\section{Ohemistry}

Commercial heparin or heparin which has undergone further purification for research purposes is not a single chemical entity. When heparin is extracted from natural sources, fractions with molecular weights between 6000 and 30,000 have been shown to have significant but variable anticoagulant activity. ${ }^{1}$ Heparins with molecular weights below 6000 have a negligible anticoagulant effect.

The basic structural unit of heparin

From the Department of Burgery, Bection of General Surgery, University of Michigan Medical Center, 1405 E. Ann Street, Ann Arbor, Mich. 48109. has now been reasonably well defined. It contains three hexose derivatives in ring form (hexopyranosides): D-glucosamine, D-glucuronic acid, and L-iduronic acid. The basic structural unit appears to be a hexasaccharide containing two disaccharides of 2-sulfoiduronic acid-2-sulfoglucosamine and one disaccharide of glucuronic acid-2-sulfoglucosamine in a 1,4alpha-glycosidic linkage. ${ }^{2}$ These units appear to be arranged in an unbranched linear chain. ${ }^{3}$ Commercial heparins contain at least 21 components with variable chain lengths of 6000 to 30,000 daltons ${ }^{4}$ and with differing elemental composition, electrophoretic mobility, and nuclear magnetic spectrum. These separate components have varying anticoagulant activity when measured by U.S.P. assay.

An important element that has not yet been clarified is the critical structural characteristic required for anticoagulant activity. Recent studies have shown that it is not one but a combination of properties which are required: free carboxyl groups, 0-sulfate ester groups on hexuronic acid, and glucosamine and the sulfamino groups of glucosamine. ${ }^{6-8}$ Alteration of shape of the molecule may also influence anticoagulant effect. ${ }^{9}$

The utilization of affinity chromatography has recently resulted in the clear demonstration of the heterogeneity of heparin on the basis of binding of heparin preparations to antithrombin III (heparin cofactor). ${ }^{10,11}$ In one commer- 
cial product, one third of the isolated material contained 85 per cent of the anticoagulant activity." "Active" and "inactive" fractions are similar in chemical composition, but the "active" material had a higher net negative charge density. ${ }^{10}$ This promising approach may result in the preparation of a product with a more consistent anticoagulant effect.

\section{Assay of Heparin}

Methods of assay of heparin in vitro may vary with the source of heparin, source of blood used in the test, and test method and may not coincide with anticoagulant or antithrombotic effect in vivo. However, no procedure has yet been demonstrated to be distinctly superior to the U.S.P. assay. Since results of bioassay of heparin from lung and intestinal mucosa have shown differences when the British and United States pharmacopoeial methods are compared, it has been suggested that the assay of heparin derived from a specific tissue be performed with a standard obtained from the same tissue and animal species and that multiple rather than single coagulation tests be used. ${ }^{12}$

The heterogeneity of heparin and the multiplicity of possible test procedures complicate the process of standardization. Heparin standards have not been characterized by physical or chemical methods. Reagents may vary from one laboratory to another. Different test methods measure different spectra of clotting factor activities. Although assay of heparin in vivo has been proposed as an alternative approach, ${ }^{13}$ it is subject to the same types of problems encountered in testing in vitro.

In spite of the many problems in the laboratory standardization of commercial heparins, clinicians have encountered few well-documented differences in apparent antithrombotic effectiveness between different products. In recent years contro- versial claims have been made concerning the superiority of heparin derived from lung as opposed to the product from intestinal mucosa. However, when controlled comparative studies have been conducted, no significant differences in anticoagulant effect have been found..$^{14-16}$ The thrombocytopenia occasionally appearing during heparin therapy has been observed with both lung and mucosal heparin. ${ }^{17,18}$ However, because of the many variables associated with the clinical assessment of antithrombotic effectiveness, the failure to observe differences does not necessarily mean they do not exist. The recent widespread use of low-dose heparin for prophylactic purposes may make accurate standardization more important since variations in potency may have greater significance under these conditions. ${ }^{19}$

\section{Absorption, Distribution, and Metabolism \\ Administration of commercial heparin} in massive doses to man by oral, buccal, or rectal routes has not resulted in significant effects upon lipemia clearing or coagulation..$^{20}$ Recently, a depolymerized low molecular weight heparin (molecular weight $4700-5300$ ) has been shown to prolong clotting times after buccal application in mice. ${ }^{21}$ The demonstration of an apparent anticoagulant effect by such low molecular weight material is unexpected and requires further confirmation.

Large doses of aqueous heparin, 1300 units or more per kilogram body weight, administered endotracheally as an aerosol will produce a moderate anticoagulant effect in man for up to 14 days. ${ }^{22}$ This observation not only indicates a possible new route for administration of heparin but also points to a potential cellular pool for heparin storage that may exist in reticuloendothelial cells from which it is slowly released into plasma.

Individual variability in absorption of

The Journal of Clinical Pharmacology 
heparin after subcutaneous injection is well recognized. Heparin may bind to tissue proteins or be inactivated by tissue enzymes, but the mechanism for variation in anticoagulant response has not yet been clarified. Lower blood levels of heparin have been detected after injection of calcium as opposed to the sodium salt. ${ }^{23}$ Since no differences are seen after intravenous injection of these two heparin salts, this difference may be related to a lesser degree of absorption of the calcium salt. This observation could explain a report of a lower frequency of hemorrhagic complications after subcutaneous administration of the calcium product. ${ }^{24}$ Others have not confirmed this difference. ${ }^{25}$

After intravenous injection of heparin in man, the apparent volume of distribution corresponds to the plasma volume. Anticoagulant half-life, as measured by clotting tests, is approximately $90 \mathrm{~min}$ utes and in the same subject does not vary significantly with size of dose. ${ }^{28}$ The disappearance of heparin is that of a first-order process. As noted above, there may be extravascular uptake by reticuloendothelial cells. ${ }^{27}$ In addition, heparin localizes on arterial and venous endothelium in concentrations as great as 7500 times its concentration in blood. ${ }^{28,29}$

There are no new important discoveries concerning the metabolism of heparin. Although it has long been recognized that only a small fraction of administered heparin is excreted unchanged in the urine, the pathways for degradation of heparin within the body have not yet been fully delineated. Progressive desulfation appears to be one important element in loss of anticoagulant activity.

\section{Mechanism of Anticoagulant Effect}

Some major recent advances have been made in our knowledge of the anticoagulant, and presumably antithrombotic, action of heparin. Although the effect of heparin upon platelet function has still not been clarified, its function in modifying clotting factor activity is much better understood.

Prothrombin is converted to thrombin by the combined action of factor $V$ and activated factor $X$ in the presence of lipid and calcium ions. In plasma there is an alpha-2 globulin (antithrombin III ; heparin cofactor) which slowly complexes stoichiometrically with thrombin through combination of an arginine group on the inhibitor with a serine center of thrombin. Heparin binds to antithrombin and markedly accelerates the interaction of thrombin and antithrombin. ${ }^{30}$ This highly specific effect of heparin upon antithrombin appears to be catalytic rather than stoichiometric. ${ }^{31}$

The heparin-antithrombin complex also initiates the rapid inhibition of other clotting factors which are serine proteases: factors XII, ${ }^{32} \mathrm{XI}^{33}$ and $\mathrm{IX}^{35}$ Kallikrein, a proteolytic enzyme involved in activation of factor XII, is also inhibited by this mechanism ${ }^{36}$ as is plasmin, the serine protease responsible for dissolution of intravascular thrombi. ${ }^{37} \mathrm{Al}$ though a slow partial inactivation of factor VII by heparin-antithrombin complex has also been reported, ${ }^{38}$ the kinetics of this reaction differ from that observed with the other clotting factors. The presence of adequate amounts of antithrombin III is essential for heparin action since patients with familial antithrombin III deficiency have been shown to have a deficient pattern of inactivation of thrombin by heparin. ${ }^{39}$

Observations concerning an effect of heparin upon platelet function have been contradictory. Heparin has been reported to induce an increase, decrease, or no change in platelet number, adhesiveness, aggregation, and release reaction. Many of these variable results may be due to the unphysiologic conditions under which the studies are carried out. ${ }^{40}$ In a recent in vivo study in rats, heparin was shown. 
to decrease adhesion of platelets to vascular endothelium. ${ }^{41}$ The tissue of origin ${ }^{42}$ and commercial source ${ }^{48}$ of heparin may also influence results.

\section{Toxicity and Hemorrbagic Complications}

Extremely rare hypersensitivity reactions and delayed transient alopecia have long been recognized and do not appear to have changed in frequency. For the past 14 years reports have appeared of rare instances of osteoporosis and compression fractures after administration of more than 10,000 units heparin per day for three months or longer. A possible mechanism for this side effect is the recent demonstration that heparin complexes with collagenase and that the complex then binds to collagen, producing a local increase in enzyme activity. ${ }^{44}$ In addition, heparin has been shown to increase the amount of procollagenase released from bone cultured in vitro. ${ }^{45}$

A great deal of interest has been expressed in heparin-associated thrombocytopenia. Although a significant decrease in platelet count has been thought to be infrequent, one recent study documents a marked decrease in platelets in 16 of 52 patients receiving five or more days of continuous heparin infusion. ${ }^{18}$ Since the pattern of platelet decrease seems to vary in different subjects, more than a single mechanism may be involved. In some instances the decrease in platelet number occurs within several minutes after heparin administration while in others the reduction in platelet count occurs over a period of two to ten days. Although some episodes appear to be immunologically mediated, ${ }^{46}$ others may be related to initiation of platelet aggregation and sequestration. ${ }^{47}$ Until more data are available concerning the frequency of a clinically significant depression of platelet, periodic monitoring of platelet number appears indicated. Measurement of platelets would be particularly impor- tant after appearance of a hemorrhagic complication since the approach to management would differ if thrombocytopenia complicates heparin-associated bleeding.

Several epidemiologic factors are known to alter the risk of bleeding during heparin therapy. Elderly patients (age 60 and over) develop hemorrhagic complications with a frequency 50 to 100 per cent greater than that of younger subjects.8.40 Of greatest importance is the presence of any disease or condition or drug that independently alters one or another phase of the hemostatic mechanism. ${ }^{50}$ One frequently neglected initiating factor is the presence of drug-induced abnormalities in patients concomitantly receiving aspirin or other drugs affecting platelet function. Administration of ethacrynic acid has been thought to potentiate the risk of bleeding during heparin therapy, but gastrointestinal bleeding is also more frequent in patients receiving ethacrynic acid alone. ${ }^{51}$

\section{Management of Heparin Therapy}

During the more than 50 years that heparin has been in clinical use, the conventional routes of administration have included continuous infusion, intermittent intravenous injection, and subcutaneous and intramuscular injection. A greater frequency of local hematoma formation has resulted in the abandonment of intramuscular injections.

There has been a recent increase in utilization of continuous infusion of hepparin, based upon the results of several prospective trials comparing this method with intermittent intravenous injection in the management of patients with venous thromboembolism. ${ }^{52,53}$ Both trials showed a very appreciable reduction in hemorrhagic complications in the groups receiving continuous infusion. In both investigations the patients receiving continuous infusions required a smaller daily dose of heparin to achieve the same level

The Journal of Clinical Pharmacology 
of anticoagulation; this reduction in heparin dosage may be responsible for the fewer hemorrhagic complications.

Although no difference in the frequency of thrombotic complications was noted in either study, the numbers of patients with recurrent thromboembolism were too small to make differentiation possible. An animal study based upon measurement of accretion of isotope-labeled fibrinogen on jugular vein thrombi in rabbits has demonstrated a significantly lesser degree of thrombus propagation when continuous infusion was compared with intermittent intravenous injection of heparin. ${ }^{54}$ A more recent third clinical trial $^{55}$ has provided contradictory data, showing no appreciable differences in total daily dosage of heparin or in hemorrhagic complications when continuous infusion and intermittent intravenous injection of heparin was compared. Although this dilemma has not been fully resolved, continuous infusion therapy may prove to be preferable if appropriate monitoring of coagulation profile indicates that lesser amounts of heparin are required and if suitable facilities and personnel are available to assure that the infusion is carried out in a proper manner.

The feasibility of continuous infusion therapy has been augmented by the availability of pumps for the regulation of constant infusion. A bolus injection of 2500 to 5000 units dilute aqueous heparin is given, and the infusion of heparin in 5 per cent dextrose is started at a rate of 1000 units per hour. Monitoring of anticoagulant effect is begun at 3 hours (approximately two anticoagulant halflives) and repeated frequently until dosage is adjusted to reach the desired endpoint for anticoagulant effect.

In the absence of a constant infusion pump, several less desirable approaches are available. A pediatric burette may be utilized, to which is added a specified volume of heparin solution at 1- to 2- hour intervals. The amount of heparin calculated for administration over a 4 hour period may be added to several hundred milliters of 5 per cent dextrose in water and given by the usual intravenous drip infusion. If the rate of administration is improperly regulated, the patient receives no more heparin than would be administered by intermittent "pulse" therapy.

An alternative, and probably the most frequently used, method is the injection of approximately 5000 units heparin (1000 units/ml) intravenously every 4 hours. Although pharmacokinetic data may indicate that more frequent injection of smaller doses would be preferable, ${ }^{26}$ such a regimen is less practicable from the nursing standpoint. Frequent "pulse" injection is greatly facilitated by a heparin "lock" (a small butterflytype needle with a rubber diaphragm connected to a plastic catheter) which is left within a superficial arm vein; suffcient heparin usually remains within the catheter to maintain patency for a considerable period. Recent data seem to indicate that monitoring anticoagulant effect in patients receiving intermittent "pulse" therapy does not reduce the frequency of bleeding, ${ }^{33}$ but monitoring at approximately 1 hour before the next injection may permit detection of an inadequate anticoagulant response and thus assure adjustment of dosage.

Standard therapeutic doses of heparin have also been given by subcutaneous injection, usually at 12-hour intervals. Aqueous concentrated heparin $(20,000$ to 40,000 units $/ \mathrm{ml}$ ) should be used since the smaller volume of solution is associated with a lower prevalence of local hematoma formation. To my knowledge a prospective trial comparing subcutaneous aqueous heparin with one of the other methods of administration in the treatment of established venous thrombosis has not been conducted to determine relative 
efficacy and safety. It is more frequently used for continued treatment of ambulatory nonhospitalized patients whose thrombotic processes appear to be refractory to oral anticoagulant therapy. It is also of considerable value in long-term therapy in pregnant patients, particularly during the first trimester, when the teratogenic hazards of oral anticoagulants should be avoided. Frequent laboratory monitoring is essential because of considerable interindividual variability in rates of absorption and possible delayed shifts of heparin from cellular pools to the intravascular compartment.

Several investigators ${ }^{56,57}$ have recommended that patients with pulmonary embolism receive one or more large initial doses of heparin $(15,000$ to 20,000 units) to attempt to reduce accretion of platelets on emboli and release of vasoactive amines ${ }^{58}$ or to neutralize the effect of release of the platelet antiheparin factor, ${ }^{50}$ but no data are available to show that this approach has an effect upon morbidity or mortality. However, patients with pulmonary embolism or other extensive thrombotic processes have been shown to have a lesser anticoagulant response to a fixed dose of heparin when monitored by the activated partial throm. boplastin time (APTT). ${ }^{60}$ During the initial hours or days of therapy these patients may require larger doses of heparin to achieve the same endpoint in anticoagulant response.

Whether routine calculation of daily dosage of heparin should be based upon body weight is debatable. Although, in general, small thin subjects appear to require lesser amounts of heparin, many other variables that affect heparin response make such estimates very uncertain.

As noted above, the safety and possibly the efficacy of heparin therapy administered by continuous infusion or sequential subcutaneous injection appears to be favorably influenced by laboratory monitoring. The procedures most commonly used for control are the APTT or the thrombin clotting time (TCT). LeoWhite clotting times have for the most part been abandoned as too cumbersome, time consuming, and inaccurate. Regardless of the method used, individual calibration and adjustment of the procedure may be necessary to assure a relatively linear response to varying levels of heparin. The APTT has a low sensitivity in detecting heparin when many commercially prepared reagents are used. ${ }^{61}$ Another concern is that a large number of hospitalized patients not receiving heparin have prolongations of the APTT. ${ }^{62}$ Some investigators have found the APTT to be less satisfactory in controlling heparin therapy than the TCT, ${ }^{63}$ factor $\mathrm{Xa}$ assay, ${ }^{64,65}$ polybrene titration, $^{86,87}$ or activated recalcification time. ${ }^{68,60}$ Since these and a number of other tests have been advocated for heparin monitoring, it is obvious that the ideal procedure has not yet been devised.

Since inter- and intraindividual variability in response to heparin is well recognized, ${ }^{26,70,60}$ monitoring of all patients receiving therapeutic doses of heparin has the potential to lessen morbidity. Prolongation by heparin of the APTT to $11 / 2$ times control will inhibit thrombosis in rabbits. ${ }^{71} \mathrm{~A}$ similar level of anticoagulation appears to be effective in man, while a lesser effect (APTT of less than 50 seconds for three consecutive days) was associated with a risk of recurrent thrombosis of 25 per cent. ${ }^{72}$ A prolongation of the APTT to $11 / 2$ to 3 times normal or the TCT to 2 to 3 times normal is roughly comparable to a two- to threefold lengthening of the Lee-White clotting time.

The optimum duration of heparin therapy for venous thromboembolism has not been determined, but later recurrence of thrombosis can be lessened by a com- 
bination of initial heparin and subsequent prolonged oral anticoagulant treatment. ${ }^{73}$ Most clinicians administer heparin for one to three weeks, the duration based upon the extensiveness of the thrombotic process. Since five to seven days of administration of oral anticoagulant is required to achieve maximum depression of vitamin $\mathrm{K}$-dependent clotting factors, heparin and oral anticoagulant treatment is overlapped for this period before heparin is stopped.

There are no new developments in the approach to reversal of the anticoagulant effect of heparin. Protamine sulfate, administered intravenously in a dose of 1.0 to $1.25 \mathrm{mg}$ per 100 units of estimated circulating heparin, remains the agent of choice. The relatively short anticoagulant half-life of intravenously administered heparin should be taken into account in estimating dose of protamine since an excess of circulating protamine also results in a transient anticoagulant effect. Sequential laboratory monitoring of coagulation should be performed because a secondary rebound may occur from dissociation of the heparinprotamine complex or from further release of heparin from cellular pools. Bleeding after subcutaneous administration of heparin requires administration of a bolus of protamine followed by an infusion of this agent over the expected period of continued absorption of the heparin from the subcutaneous depot.

\section{Other Ifffects of Heparin}

The mechanisms involved in the lipolytic effect of heparin ${ }^{74,75}$ and the numerous other "side effects" of heparin" have been reviewed elsewhere. A recently discovered ancillary effect of heparin which has reached the clinical horizon is the infusion of solutions of heparin via a tube in the common bile duct to attempt to achieve the dissolution of retained gallstones. This therapy has been based upon the concept that the high electronegative charge on the heparin molecule might improve colloidal suspension stability of bile by altering particle surface charge and thus cause gallstones to fragment. ${ }^{77} \mathbf{R e}$ sults with this approach have been variable. ${ }^{78-80}$ The successful results may be secondary to the flushing effect of the continuous infusion into the common bile duct since infusion of saline alone has also been effective. ${ }^{81}$

\section{Other Clinical Applications}

In the past ten years the gradual evolution of the use of heparin for the prophylaxis of venous thromboembolism has produced a major increase in total amount of heparin administered. The potential value of the utilization of smaller amounts of heparin injected subcutaneously for prevention of postoperative venous thromboembolism was first reported by Sharnoff ${ }^{82}$; its widespread use in the past five years has followed confirmation of the effectiveness of this routine in prospective controlled trials in which the frequency of thrombosis has been documented with $\mathrm{I}^{125}$-fibrinogen scanning.

The rationale for this "low dose" regimen is based upon the concept that lesser amounts of heparin are needed to prevent the initiation of a thrombus than to prevent its propagation. Small amounts of heparin markedly increase the rate of inhibition of activated factor $\mathrm{X}(\mathrm{Xa})$ by antithrombin III. One microgram of antithrombin-heparin complex, by inhibiting the activity of 32 units $\mathrm{Xa}$, prevents the potential activation of 1600 units thrombin; the neutralization of this amount of thrombin would require 1000 micrograms antithrombin. ${ }^{83}$ It is possible that this suppression of thrombus development may also be mediated by more rapid inhibition of other activated serine proteases (XIIa, XIa, IXa), but this has not yet been proved. 
Although dozens of controlled trials utilizing labeled fibrinogen or venography for diagnosis have been published in the past few years, the scope of effectiveness and limitations of low-dose heparin therapy have not yet been fully defined. The majority of these studies have been conducted in surgical patients. In 17 of 19 studies of patients undergoing thoracic, abdominal, or urologic operations that have been recently summarized, ${ }^{84}$ a significant reduction in postoperative thrombosis was observed. The mean decrease in frequency of venous thrombosis was about threefold. However, this approach is of no or very limited value in orthopedic patients, particularly those with femoral fractures and reconstructive procedures about the hip and knee, and urologic patients having an open prostatectomy; its efficacy in patients undergoing total removal of the rectum for cancer is also uncertain. More severe direct venous trauma and possible increased activation of the clotting mechanism through the release of thromboplastic agents from tissues have been proposed as possible mechanisms to explain the failure of low-dose heparin under these circumstances.

This prophylactic regimen is effective in reducing the frequency of leg vein thrombosis in patients with acute myocardial infarction and congestive heart failure. ${ }^{85,88}$ Although it should also be of value in other medical and neurologic patients who are at increased risk of venous thrombosis because of paralysis, confinement to bed, etc., appropriate controlled studies have not yet been conducted.

Since the prevalence of leg vein thrombi detected by labeled fibrinogen is 10 to 50 per cent in high-risk medical and surgical patients, the clinical importance of reducing the frequency of these thrombi, most of which are confined to the calf veins, has been questioned.
Several recent investigations have now confirmed that in suitable subjects, as mentioned above, low-dose heparin also reduces the frequency of iliofemoral venous thrombi ${ }^{87}$ and of nonfatal and fatal pulmonary embolism. ${ }^{\mathbf{8 8 , 8 0}}$

Most of the controlled trials have used one of two standard dosage regimens: the injection of 5000 units aqueous concentrated heparin at 8-hour or 12-hour intervals. Heparin should be in concentrated form $(20,000$ units $/ \mathrm{ml})$, and volume should be accurately measured to minimize the risk of hemorrhage. In surgical patients the first dose is usually administered 2 hours before operation and continued postoperatively until the patient is fully ambulatory. However, in one recent study of surgical patients admitted to the hospital more than four days before operation, 62 per cent of all leg vein thrombi which were detected appeared before the operation. ${ }^{90}$ This observation points to a need for earlier heparin prophylaxis in patients requiring extensive preoperative investigations. Bleeding has not been a problem in the majority of trials utilizing a twice-daily dosage routine, while there has been a small increase in operative blood loss and postoperative bleeding in patients receiving heparin every 8 hours. Although the three-times-daily regimen was instituted in an attempt to achieve a greater antithrombotic effect in highrisk patient groups, these two routines have not yet been compared for riskbenefit ratio in prospective studies. At present the use of low-dose heparin is contraindicated in patients having spinal or epidural anesthesia and operations upon the brain, spinal cord, or eye.

The limited effectiveness of low-dose heparin in certain orthopedic patients has stimulated interest in the utilization of combinations of heparin and dextran or heparin and aspirin. No appropriately controlled studies have been reported; the significant increase in hemorrhagic

The Journal of Clinical Pharmacology 


\section{PHARMACOLOGY OF HEPARIN}

risk when two agents affecting different phases of hemostasis are given in combination should be appreciated. ${ }^{50} \mathrm{~A}$ randomized trial of patients undergoing total hip replacement has compared the effect of low-dose heparin alone with low-dose heparin plus dihydroergotamine and reported a significant reduction in leg vein thrombosis in the latter group. ${ }^{84}$ Dihydroergotamine is thought to have an additive effect by increasing venous flow and possibly by stimulating the release of plasminogen activator from the vein wall.

Although sufficient data are available to suggest that the broad use of low-dose heparin prophylaxis will reduce the frequency of fatal pulmonary embolism, the issues of patient selection and cost-benefit ratio have not yet been resolved. Most trials in surgical subjects have encompassed all patients age $\mathbf{4 0}$ years and over undergoing major operations. If these criteria are utilized, the population at risk is extremely large; the demands on heparin production and the increase in nursing load would be appreciable. Further restriction of criteria for patient selection may be necessary in order to make this prophylactic approach cost effective. ${ }^{01}$ This will be particularly important if the well-recognized interindividual variability in response to a fixed dose of heparin necessitates laboratory monitoring of low-dose heparin routines in order to lessen the increased frequency of bleeding.

Another clinically applicable innovation is the development of methods for bonding of heparin to biomaterials. The transient placement of catheters within arteries and veins and the more permanent placement of prosthetic materials in the cardiovascular system has led to a search for materials less susceptible to thrombus formation. Over the past 15 years techniques have been developed for the bonding of heparin to polystyrene, polyethylene, poly (vinyl chloride), collagen, silicon rubber, nylon, etc. ${ }^{92}$ Heparin has also been bonded to a polyester fiber that can be subsequently knitted or woven into tubular vascular prostheses. A current popular method for bonding involves the application to the material of a complex of tridodecylmethylammonium chloride and heparin.92 Gamma irradiation has also been shown to bond heparin to cellular membranes. ${ }^{93}$

Many heparin-bonded foreign surfaces have not inhibited platelet adhesion and subsequent platelet embolism, ${ }^{94}$ but a polyurethane-heparin complex ${ }^{95}$ and heparin-bonded polyethylene ${ }^{\theta 6}$ appear to have some effect upon inhibition of platelet deposition. The mechanism of resistance to thrombus formation by heparinbonded surfaces is still being debated; some studies show a delay in coagulation when blood is in contact with such a surface, ${ }^{97}$ while others attribute the effect to slow leaching of heparin from the material. There is some preferential adsorption of antithrombin III, factors IX and $\mathrm{XI}$, and thrombin to the bonded surface. ${ }^{98}$

Large heparin-bonded catheters have been used in man for temporary bypass of the descending thoracic aorta during insertion of a prosthetic vascular graft. ${ }^{.9}$ A very practical future application would be the development of smaller heparinbonded vascular catheters. ${ }^{100,101}$ Since these catheters, which are currently left in blood vessels for periods that vary from hours to days or weeks, rapidly develop a sleeve of fibrin which may occlude the vessel or catheter lumen or embolize, any development that might lessen the frequency of these complications would be of considerable practical value.

\section{References}

1. MaDuffie, N. M., Dietrich, C. P., and Nader, H. B.: Electrofocusing of heparin-fractionation of heparin into $21 \mathrm{com}$. ponents distinguishable from other acidic 
mucopolysaccharides. Biopolymers 14: 1473 (1975).

2. Perlin, A. S., Mackie, D. M., and Dietrich, C. P.: Evidence of 1-4 linked 4-0- $\alpha$-Lidopyranosyluronic acid (2-sulfate)- 2deoxy-2-sulfamino-D-glycopyranolsyl (6sulfate) sequence in heparin. Carbohydr. Res. $18: 185$ (1971).

3. Silvan, M. E., and Dietrich, C. P.: Structure of heparin. J. Biol. Chem. 250:6841 (1975).

4. Nader, H. B., McDuffie, N. M., and Dietrich, C. P.: Heparin fractionation by electrofocusing: presence of 21 components of different molecular weights. Biochem. Biophys. Res. Commun. 57:488 (1974).

5. Jaques, L. B., and Kavanaugh, L. W.: Variability of heparin preparations in clinical use. Thromb. Haemostas. Suppl. $56: 171$ (1973).

6. Cifonelli, J. A.: The relationship of molecular weight and sulfate content and distribution to anticoagulant activity of heparin preparations. Carbohydr. Res. 37 : 145 (1974).

7. Danishefsky, I.: Synthesis and properties of heparin derivatives. Advan. Exp. Med. Biol. $52: 105$ (1975).

8. Jorpes, J. E., Bostrom, H., and Mutt, V.: The linkage of the amino group in heparin. J. Biol. Chem. 183:607 (1950).

9. Kiss, J.: Chemical structure of heparin. In Heparin: Chemistry and Clinical Usage, Kakkar, V. V., and Thomas, D. P., Eds. New York, Academic Press, 1976, p. 3.

10. Höök, M., Björk, I., Hopwood, J., and Lindahl, U.: Anticoagulant activity of heparin: separation of high-activity and low activity heparin species by affinity chromatography on immobilized antithrombin. FEBS Lett. 66:90 (1976).

11. Lam, L. H., Silbert, J. E., and Rosenberg, R. D.: The separation of active and inactive forms of heparin. Biochem. Biophys. Res. Commun. 69:570 (1976).

12. Bangham, D. R., and Woodward, P. M.: A collaborative study of heparins from different sources. Bull. WHO $42: 129$ (1970).

13. Kuo, S. H., Jaques, L. B., and Millar, G. I.: An improved in vivo procedure for standardization of heparin preparations. J. Pharm. Pharmacol. 24:858 (1972).

14. Baltes, B. J., Diamond, S., and D'Agostino, R. J.: Comparison of anticoagulant activity of two preparations of purified heparin. Clin. Pharmacol. Therap. 14:287 (1973).

15. Gomez-Perez, F.: Anticoagulant activity of two commercially available heparin preparations. A controlled study. J. Clin. Pharmacol. 12:413 (1972).
16. McMahon, F. G., Jain, A. K., Ryan, J. R., and Lefton, T. E.: Anticoagulant potency of mucosal and lung heparin. Clin. Pharmacol. Therap. 17:79 (1975).

17. Bell, W. R.: Thrombocytopenia occurring during heparin therapy. New England J. Med. $295: 276$ (1976).

18. Bell, W. R., Tomasulo, P. A., Alving, B. M., and Duffy, T. P.: Thrombocytopenia occurring during the administration of heparin: a prospective trial in 52 patients. Ann. Int. Med. 85:155 (1976).

19. Jaques, L. B.: Standardization of heparin for clinical use. Lancet 1:287 (1975).

20. Windsor, E., and Freeman, L.: An investigation of routes of administration of heparin other than injection. Amer. $J$. Med. $37: 408$ (1964).

21. Lasker, S. E.: Low-molecular-weight derivative of heparin that is orally active in mice. Advan. Exp. Med. Biol. 52:119 (1975).

22. Jaques, L. V., Mahadoo, J., and Kavanaugh, L. W.: Intrapulmonary heparin. A new procedure for anticoagulant therapy. Lancet 2:1157 (1976).

23. Thomas, D. P., Sagar, S., Stomatakis, J. D., Maffei, F. H. A., Erdi, A., and Kakkar, V. V.: Plasma heparin levels after administration of calcium and sodium salts of heparin. Thromb. Res. 9:241 (1976).

24. Whitehead, M. I., and McCarthy, T. G.: A comparative trial of subcutaneous sodium and calcium heparin as assessed by local hematoma formation and pain. In Heparin: Chemistry and Clinical Use, Kakkar, V. V., and Thomas, D. P., Eds. New York, Academic Press, 1976, p. 361.

25. Bergquist, D., and Hallbook, T.: Are there any differences in thrombosis prophylaxis and side-effects between sodium and calcium heparin Proc. Sixth International Congress on Thrombosis and Haemostasis, Bala Cynwyd, Pa., June 26July 2, 1977. Thromb. Haemostas. 38(1) : 106 (1977).

26. Estes, J. W.: The fate of heparin in the body. Curr. Therap. Res. 18:45 (1975).

27. Jaques, L. B., Mahadoo, J., and Riley, J. F.: The mast cell/heparin paradox. Lancet 1:411 (1977).

28. Essien, E. M., Kinlough-Rathbone, R., Moore, S., and Mustard, J. F.: The role of heparin on the inhibition of platelet adhesion to damaged arterial endothelial surfaces. Thromb. Haemostas. 34:600 (1975) (Abstr.).

29. Hiebert, L. M., and Jaques, L. B.: The observation of heparin on endothelium after injection. Thromb. Res. 8:195 (1976).

The Journal of Clinical Pharmacology 
30. Li, E. H. H., Fenton, J. W., II, and Feinman, R. D.: The role of heparin in the thrombin-antithrombin III reaction. Arch. Biochem. Biophys. 175:153 (1976).

31. Björk, I., and Nordenman, B.: Acceleration of the reaction between thrombin and antithrombin III by non-stoichiometric amounts of heparin, Europ. J. Biochem. 68:507 (1976).

32. Stead, N., Kaplan, A. P., and Rosenberg, R. D.: Inhibition of activated factor XII by antithrombin-heparin cofactor. $J$. Biol. Chem. 251:6481 (1976).

33. Damus, P. S., Hicks, M., and Rosenberg, R. D.: Anticoagulant action of heparin. Nature $246: 355$ (1973).

34. Yin, E. T., Wessler, S., and Stoll, P. J.: Identity of plasma-activated factor $X$ inhibitor with antithrombin III and heparin cofactor. J. Biol. Chem. 246:3712 (1971).

35. Rosenberg, J. S., McKenna, P. W., and Rosenberg, R. D.: Inhibition of human factor IXa by human antithrombin. $J$. Biol. Chem. $250: 8883$ (1975).

36. Burrowes, C. E., Habal, F. M., and Movat, H. Z.: The inhibition of human plasma kallikrein by antithrombin III. Thromb. Res. 7:175 (1975).

37. Highsmith, R. F., and Rosenberg, R. D.: The inhibition of human plasmin by human antithrombin-heparin cofactor. $J$. Biol. Chem. $249: 4335$ (1974).

38. Godal, J. C., Rygh, M., and Laake, K.: Progressive inactivation of purified factor VII by heparin and antithrombin III. Thromb. Res. 5:773 (1974).

39. Marciniak, E., Farley, C. H., and DeSimone, P. A.: Familial thrombosis due to antithrombin III deficiency. Blood 43: 219 (1974).

40. Han, P., and Ardlie, N. G.: Heparin, platelets and blood coagulation: implications for low-dose heparin prophylactic regimens in venous thrombosis. Brit. $J$. Haematol. $27: 253$ (1974).

41. Gregorius, F. K., and Rand, R. W.: Scanning electron microscopic observations of the common carotid artery of the rat. III. Heparin effect on platelets. Surgery $79: 584$ (1976).

42. Kwaan, H. C., and Hatem, A.: Effect of lung and gut heparin on experimental arterial thrombosis. Advan. Exp. Biol. Med. 52:263 (1975).

43. Eika, C.: The platelet-aggregating effect of eight commercial heparins. Scand. $J$. Hacmatol. 9:480 (1972).

44. Sakamoto, S., Sakamoto, M., Goldhaber, P., and Glimcher, M. J.: Studies on the interaction between heparin and mouse bone collagenase. Biochem. Biophys. Acta 395:41 (1975).
45. Lenaers-Claeys, G., and Vaes, G.: Conditions governing the release of collagenase and procollagenase by bone explants in culture: effects of heparin. Arch. Int. Physiol. Biochim. 84:634 (1976).

46. Babcock, R. B., Dumper, C. W., and Scharfman, W. B.: Heparin-induced immune thrombocytopenia. New England J. Med. 295:237 (1976).

47. Davey, M. G., and Lander, H.: Effect of injected heparin upon platelet levels in man. J. Clin. Pathol. 21:55 (1968).

48. Coon, W. W., and Willis, P. W.: Hemorrhagic complications of anticoagulant therapy. Arch. Int. Med. $133: 386$ (1974).

49. Jick, H., Slone, D., Borda, I., and Shapiro, S.: Efficacy and toxicity of heparin in relation to age and sex. New England J. Med. $279: 284$ (1968).

50. Jaques, L. B.: Stress and multiple-factor etiology of bleeding. Ann. New Fork Acad. Sci. $115: 78$ (1964).

51. Slone, D., Jick, H., Lewis, G. P., Shapiro, S., and Miettinen, O. S.: Intravenously given ethacrynic acid and gastrointestinal bleeding. J.A.M.A. $209: 1668$ (1969).

52. Glazier, R. L., and Crowell, E. B.: Randomized prospective trial of continuous versus intermittent heparin therapy. J.A.M.A. $236: 1365$ (1976).

53. Salzman, E. W., Deykin, D., Shapiro, R. M., and Rosenberg, R. D.: Management of heparin therapy; controlled prospective trial. New England J. Med. 292: 1042 (1975).

54. Chiu, H. M., Hirsh, J., Yung, W. L., Rogoeczi, E., and Gent, M.: Relationship between the anticoagulant and antithrombotic effects of heparin in experimental venous thrombosis. Blood 49:171 (1977).

55. Mant, M. J., O’Brien, B. D., Thong, $\mathbf{K}$. L., Hammand, G. W., Birtwhistle, R. U., and Grace, M. G.: Hemorrhagic complications of heparin therapy. Lancet 1: 1133 (1977).

56. Genton, E.: Guidelines for heparin therapy. Ann. Int. Med. 80:77 (1974).

57. Silver, D.: Pulmonary embolism: prevention, detection and non-operative management, Surg. Clin. North Amer. 54: 1089 (1974).

58. Gurewich, V., Cohen, M., and Thomas, D. P.: Humoral factors in massive pulmonary embolism. Amer. Heart J. 76: 784 (1968).

59. Thomas, D. P.: Therapeutic role of heparin in acute pulmonary embolism. Curr. Therap. Res. 18:21 (1975).

60. Hirsh, J., Van Aken, W. G., Gallus, A. S., Dollery, C. T., Cade, J. F., and Yung, W. L.: Heparin kinetics in venous 
thrombosis and pulmonary embolism. Circulation 58:691 (1976).

61. Soloway, H. B., Cornett, B. M., and Grayson, J. W., Jr.: Comparison of various activated partial thromboplastin reagents on the laboratory control of heparin therapy. Amer. J. Clin. Pathol. 59: 587 (1973).

62. Teien, A. N., and Abildgaard, U.: On the value of the activated partial thromboplastin time (APTT) in monitoring heparin therapy. Thromb. Haemostas. 35: 592 (1976).

63. Penner, J. A.: Experience with a thrombin clotting time assay for measuring heparin activity. Amer. J. Clin. Pathol. $61: 645$ (1974).

64. Denson, K. W. E., and Bonnar, J.: The measurement of heparin. A method based upon the potentiation of anti-factor Xa. Thromb. Haemostas. 30:471 (1973).

65. Yin, E. T., Wessler, W., and Butler, J. V.: Plasma heparin: a unique, practical, submicrogram-sensitive assay. J. Lab. Clin. Med. $81: 298$ (1973).

66. Grann, V. R., Homewood, $K$., and Golden, W.: Polybrene neutralization as a rapid means of monitoring blood heparin levels. Amer. J. Clin. Pathol. 58:26 (1972).

67. Teien, A. M., and Lie, M.: Heparin assay in vitro: a comparison of five clotting assays. Thromb. Res. 7:777 (1975).

68. Congdon, J. E., Kardinal, C. G., and Wallin, J. D.: Monitoring heparin therapy in hemodialysis. J.A.M.A. 226:1529 (1973).

69. Jaberi, M., Bell, W. R., and Benson, D. W.: Control of heparin therapy in open heart surgery. J. Thorac. Cardiovasc. Surg. $67: 133$ (1974).

70. Goodman, T. L., Todd, M. E., and Goldsmith, E. I.: Laboratory observations and clinical implications of monitoring the effect of heparin by bioassay. Surg. Gynecol. Obstet. 142:673 (1976).

71. Zucker, S., and Cathey, M. H.: Control of heparin therapy. Sensitivity of the activated partial thromboplastin time for monitoring the antithrombotic effect of heparin. J. Lab. Clin. Med. 73:320 (1969).

72. Basu, D., Gallus, A., Hirsh, J., and Cade, J.: A prospective study of the value of monitoring heparin treatment with activated partial thromboplastin time. New England J. Med. $287: 324$ (1972).

73. Coon, W. W., and Willis, P. W., III : Recurrence of venous thromboembolism. Surgery 73:823 (1973).

74. Brown, W. V., Shaw, W., Baginsky, M., Boberg, J., and Augustin, J.: Lipases and lipoprotein. In Lipoprotein Metabo- lism, Greten, H., Ed. Berlin, SpringerVerlag, 1976, p. 2.

75. Olivecrona, T., Bengtsson, G., Marklund, S. E., Lindahl, U., and Höök, M.: Heparin-lipoprotein lipase interactions. $F e d$. Proc. 36:60 (1977).

76. Coon, W. W., and Willis, P. W., 3rd: Some side effects of heparin, heparinoids and their antagonists. Clin. Pharmacol. Therap. 7:379 (1966).

77. Ostrowitz, A., and Gardner, B.: Studies of bile as a suspending medium and its relationship to gallstone formation. Surgery $68: 329$ (1970).

78. Gardner, B.: Experiences with the use of intracholedochal heparinized saline for the treatment of retained common duct stones. Ann. Surg. 177:240 (1973).

79. Mok, H. Y. I., Bell, G. D., Whitney, B., and Dowling, R. H.: Stones in common bile duct: non-operative management. Proc. Roy. Soc. Med. 67:658 (1974).

80. Patterson, H. C.: Heparin as a resolvent agent of residual common duct stones. Gastroenterology 64:781 (1973) (Abstr.)

81. Catt, P. B., Hogg, D. F., Clunie, G. J. A., and Hardie, I. R.: Retained biliary calculi: removal by a simple non-operative technique. Ann. Surg. 180:247 (1974).

82. Sharnoff, J. G.: Results in the prophylaxis of postoperative thromboembolism. Surg. Gynecol. Obstet. 123:303 (1966).

83. Wessler, S.: Prevention of venous thromboembolism by low-dose heparin. Mod. Concepts Cardiovasc. Dis. 45:105 (1976).

84. Kakkar, V. V.: The current status of lowdose heparin in the prophylaxis of thrombophlebitis and pulmonary embolism. World J. Surg. 2:3 (1978).

85. Gallus, A. S., Hirsh, J., Tuttle, R. J., Trebilcock, R., O'Brien, S. E., Carroll, J. J., Minden, J. H., and Hudecki, s. M.: Small subcutaneous doses of heparin in prevention of venous thrombosis. New England J. Med. 288:551 (1973).

86. Warlow, C., Beattie, A. G., Terry, G., Ogston, D., Kenmure, A. C. F., and Douglas, A. S.: A double blind trial of low doses of subcutaneous heparin in the prevention of deep vein thrombosis after myocardial infarction. Lancet 1:934 (1974).

87. Gallus, A. S., Hirsh, J., O'Brien, S. E., McBride, J. A., Tuttle, R. J., and Gent, $M .:$ Prevention of venous thromboembolism with small subcutaneous doses of heparin. J.A.M.A. $235: 198$ (1976).

88. International Multicentre Trial: Prevention of fatal postoperative pulmonary embolism by low doses of heparin. Lancet $2: 45$ (1975).

89. Sagar, S., Massey, J., and Sanderson, J. 
M.: Low-dose heparin in prophylaxis against fatal pulmonary embolism. Brit. Med. J. 4:257 (1975).

90. Heatley, R. V., Hughes, L. E., Morgan, A., and Okwonga, W.: Preoperative or postoperative deep vein thrombosis. Lancet $1: 437$ (1976).

91. Coon, W. W.: Epidemiology of venous thromboembolism. Ann. Surg. 186:149 (1977).

92. Grode, G. A., Anderson, S. J., Grotte, H. M., and Falb, R. D.: Non-thrombogenic materials via a simple coating process. Trans. Amer. Soc. Artif. Int. Organs 15: 1 (1969).

93. Chawla, A. S., and Chang, T. M. S.: Nonthrombogenic surface by radiation grafting of heparin: preparation, in vitro and in vivo studies. Biomater. Med. Devices Artif. Organs 2:157 (1974).

94. Salzman, E. W., Merrill, E. W., Binder, A., Wolf, C. F. W., Ashford, T. P., and Austen, W. G.: Protein-platelet interaction on heparinized surfaces. J. Biomed. Mater. Res. 3:69 (1969).

95. Rembaum, A., Yen, S. P. S., Ingram, M., Newton, J. F., and Hu, C. L.: Platelet adhesion to heparin-bonded and heparin- free surfaces, Biomater. Med. Devices Artif. Organs 1:99 (1973).

96. Jacobsson, B., and Schlossman, D.: Thrombogenic properties of heparinized vascular catheters. Acta Radiol. 14:569 (1973).

97. Dudley, B., Williams, J. L., Able, K., and Muller, B.: Synthesis and characterization of blood compatible surfaces. Dynamic tube test applied to heparinized surfaces. Trans. Amer. Soc. Artif. Int. Organs 22:538 (1976).

98. Gentry, P. W., and Alexander, B.: Specific coagulation factor absorption to insoluble heparin. Biochem. Biophys. Res. Commun. 50:500 (1973).

99. Brenner, W. I., Engelman, R. M., Williams, C. D., Boyd, A. D., and Reed, G. E.: Non-thrombogenic aortic and vena caval bypass using heparin-coated tubes. Amer. J. Surg. 127:555 (1974).

100. Gott, V. L.: Wall-bonded heparin-historical background and current clinical applications. Advan. Exp. Med. Biol. 52 : 351 (1975).

101. Hawkins, I. F., and Kelly, M. J.: Benzalkonium-heparin-coated angiographic catheters. Radiology 109:589 (1973). 